\title{
Prison Personnel: Burnout, Stress Reactions, and Intent to Quit
}

\author{
Setti llaria \\ PhD, University of Pavia, Department of Brain and Behavioral Sciences, Unit of Applied Psychology \\ Email: ilaria.setti@unipv.it \\ Argentero Piergiorgio \\ University of Pavia, Department of Brain and Behavioral Sciences, Unit of Applied Psychology \\ Email: piergiorgio.argentero@unipv.it
}

\section{Doi:10.5901/mjss.2015.v6n3s1p612}

\begin{abstract}
The ultimate aim of the present research was to examine well-being of prison Correctional Officers (COs), in particular we have analyzed predictors of burnout and psychosomatic symptoms, and variables affecting job dissatisfaction and intent to quit. 108 self-report questionnaires examining occupational stressors, burnout, psychosomatic symptoms, job dissatisfaction, and intent to quit were collected in an Italian public prison. First of all, the findings revealed that participants showed neither significant burnout nor psychosomatic complaints; this result may be partially explained by the specific-police "macho" culture, the fear of appearing weak which causes the need to show emotions different from the real ones. Furthermore, burnout is mainly affected by the quality of interactions, in terms of stressful contacts, with inmates whereas psychosomatic symptoms by stressful relationships with colleagues and superiors. Finally, the intent to quit the current job, which was found to be rather low, was affected by burnout, in particular by emotional exhaustion. Overall considered, our results suggest some applicative implications, and especially the importance to provide useful strategies, at both organizational and individual level, which may support COs in coping with occupational stressors. In particular, counseling may be effective in preventing emotional distress and in reducing sickness absence caused by the contact with problematic inmates.
\end{abstract}

Keywords: prison Correctional Officers; burnout; psychosomatic symptoms; job dissatisfaction; intent to quit

\section{Introduction}

Prison Correctional Officers (COs) are exposed to multiple stressors, which may negatively affect their health: according to the Health and Safety Executive (2006), this professional population has the highest absences for sickness, mainly due to psychological conditions, such as anxiety, depression and muscular-skeletal problems.

In the present research, we aim to investigate the mechanisms by which work-related variables may affect COs' well-being. Our interest is to contribute to the understanding of the link between organizational characteristics and individual well-being. More in detail, the ultimate goal of the present study is to map the typical stressors affecting individuals working in the prison system, to assess the outcomes resulting from these stressors, and to suggest ways to reduce burnout and stress reactions.

To date, the psychological support offered in prisons is commonly directed to inmates, aiming to help them to overcome typical problematic aspects such as self-harm behaviors, suicidal ideation, and substance abuse (Towl, 2005). Even if this type of psychological support is essential, more attention should be given also to psychological support for prison staff: a psychological service aimed at better face stress and trauma could increase the life quality of those who work in prisons (Xanthakis, 2009). In regard to this topic, research concerning the well-being of prison staff has been mainly developed in the US (Dowden \& Tellier, 2004), while less studies have been carried out in Europe, mainly in UK (Talbot-Landon, Palmer, \& Flaxman, 2007), Sweden and the Netherlands. In the light of these considerations, the present study aims to increase the research in the field of prison staff's well-being in the European, to be more precise in the Italian, socio-cultural context. From an applicative perspective, this type of research may support welfare professionals in developing specialized services aimed at helping prison staff with various issues (such as physical illness or transfers), and in offering early psychological support that COs could easily access not only after a critical event, but also to prevent emotional distress in response to chronic stressors. 


\subsection{Stressors among prison prison Correctional Officers (COs)}

In general, one of the main sources of stress for COs is high workload, that have been reported by about $70 \%$ of these professionals (Kommer, 1990): they have often to carry out several tasks in short periods, with brief recovery intervals (Prati \& Boldrin, 2011). Moreover, they are daily exposed to contact with prison inmates, who are often agressive, angry and mentally unstable individuals (Lambert, Edwards, Camp, \& Saylor, 2005).

Literature offers several classifications of prison employees' stressors, such as that proposed by Senol-Durak and colleagues (2006), who have identified five categories of work stressors. In the present study, we chose to adhere to the classification proposed by Keinan and Malach-Pines (2007), on the basis of the empirical results of their research carried out on 496 prison employees. Their four categories of occupational stressors are: a) stressful contact with others (noninmates), referred to unfair treatment by superiors, confrontations with coworkers, and negative public image of COs; b) stressful contact with inmates, which concerns contacts with drug abusers, people who committed serious crimes, and conflicts between inmates' guarding and rehabilitation; c) organizational stressors, which deals with shift work, overload, and heavy responsibilities; d) inconsiderate practices by management, referred to performing extra shifts without financial compensation, overtime, and superiors' preferential attitudes toward inmates versus COs.

These stressors may produce different reactions, mainly in terms of burnout and psychosomatic symptoms.

\subsection{Burnout and psychosomatic symptoms}

Burnout is one of the health outcomes most frequently reported by COs (Schaufeli \& Peeters, 2000) together with general stress, substance abuse, post-traumatic and psychosomatic complaints. It is a form of stress typical of helping professions: for example, police officers often experience higher rates of burnout than other professions (Dowler, 2005). Burnout has been described as a syndrome characterized by emotional exhaustion, depersonalization, and professional inefficacy (Maslach \& Jackson, 1986), attributable to chronic stressful work conditions. Emotional exhaustion is a feeling of being overextended and it is caused by daily interactions with the public; depersonalization is an unconscious defense strategy adopted to face the emotional exhaustion, and it consists in maintaining a distance from people and decreasing investment in human relationships; professional inefficacy is a result of the cynical attitude, that produces feelings of incompetence and unsuccessful achievement of one's work with people (Maslach \& Jackson, 1986).

Beyond burnout, COs may develop other symptoms, such as loss of sleep, hypervigilance and numbing, that in most cases are transitory and can be solved through, for example, social support by family and colleagues (Chapin, Brannen, Singer, \& Walker, 2008). Psychosomatic troubles could be considered as the effect deriving from the exposure to occupational stressors (Setti \& Argentero, 2013). In the present research, we were interested in studying symptoms that are typical of minor psychiatric disorders: general dysphoria - referred to the presence of psychosomatic symptoms social dysfunction - which indicates difficulties in social performing and in facing problems - and loss of confidence - in terms of low self-esteem.

The first aim of the present study was to verify, in an explorative perspective, the incidence of job stressors and the level of well-being in a sample of Italian COs. In line with previous research (see for example Keinan \& Malach-Pines, 2007; Prati \& Boldrini, 2011), we assumed that they are exposed to several stressors and, therefore, that they show malaise symptoms, in terms of burnout and psychosomatic symptoms.

The second aim was to verify if the examined demographic variables - age and work seniority - are associated with different levels of burnout. In line with previous findings (see for example Xanthakis, 2009), we assumed that older COs, with a higher work seniority, are at higher risk to develop burnout.

Based on findings of Xanthakis (2009), who showed that problematic interactions with inmates may be related to stress and burnout, our third aim was to identify, among the considered job stressors, the main predictors of burnout and psychosomatic symptoms.

\subsection{Job satisfaction and Intent to quit}

As previously demonstrated by other researchers (see for example Aiken, Clarke, Sloane, Sochalski, \& Silber, 2002; Lake, 1998), job satisfaction and intent to quit represent interesting variables to consider among helping professions.

Job satisfaction can be defined as a pleasurable or positive emotional state resulting from the appraisal of one's job (Toga, Binqela \& Mjoli, 2014). In other words, it is the extent to which people like (satisfaction) or dislike (dissatisfaction) their jobs (Sekaran, 1999). Another definition was provided by Temple and Gillespie (2009) who defined job satisfaction as the feeling that is experienced after a task is accomplished, and this feeling could be negative or 
positive depending on the outcome of the task undertaken.

Burnout and job dissatisfaction have been recognized as important precursors of the intention to leave the current job in helping professions, such as nurses (Aiken et al., 2002; Lake, 1998). This represents an interesting topic from an applicative point of view because voluntary turnover may, in turn, contribute to understaffing, and so to higher workload, and to lower users' outcomes (Aiken et al., 2002). Supportive human resource management practices elicit employees' positive reactions in terms, for example, of increased commitment and lower intent to quit, which in turn decrease actual turnover (Meyer, Allen, \& Smith, 1993).

Based on previous research (Aiken et al., 2002; Lake, 1998), the fourth aim of this study was to verify the influence of burnout and job dissatisfaction on the intent to quit.

\section{Research Methods}

\subsection{Procedure and participants}

A survey was conducted on COs working in a public prison located in the Northetn Italy. A total of 210 questionnaires were delivered to all the officers. They received the written questionnaire with a cover letter asking for their participation voluntary and anonymous - in this study.

Of the 210 questionnaires distributed, 108 (51.43\%) were completed and returned. Participants' mean age was 39.02 years $(S D=8.62)$ and their mean work seniority was 16.74 years $(S D=9.44)$.

\subsection{Measures}

Stressors Questionnaire. The items of this instrument (Keinan \& Malach-Pines, 2007) are grouped in the four factors, corresponding to COs' occupational stressors: 1) stressful contact with non-inmates (11 items, e.g. "Confrontations with coworkers", $a=.87) ; 2$ ) stressful contact with inmates (10 items, e.g. "Contact with drugs and drug users", $a=.85) ; 3$ ) organizational stressors (6 items, e.g. "Shift work", $\alpha=.82) ; 4$ ) inconsiderate practices by management (4 items, e.g. "Extra shift with no compensation", $a=.82$ ). Each item is rated on a scale ranging from 1 (not stressful at all) to 5 (extremely stressful).

Burnout. The Maslach Burnout Inventory-General Survey (MBI-GS; Schaufeli, Leiter, Maslach, \& Jackson, 1996) is the most frequently used instrument to assess burnout among helping professions (Schaufeli \& Enzmann, 1998). In the present research, we chose to administer two of the three subscales: the professional inefficacy was not used because "Of the three MBI dimensions, exhaustion and cynicism are the two primary measures of burnout ... In other words, these two dimensions "go together"- they both appear strongly in people experiencing burnout ... Thus, a potential early warning sign is the presence of one of these two dimensions, but not the other" (referring to professional inefficacy; Maslach \& Leiter, 2008, p. 501; see also Schaufeli et al., 2009). The 10 items are grouped into the following sub-scales: emotional exhaustion (5 items, e.g. "I feel emotionally drained from my work", a=.91) and depersonalization (5 items, e.g." I have become less interested in my work since I started this job", $a=.88$ ). The responses are based on a seven-point Likert scale that indicates the frequency of experiencing each burnout manifestation from 0 (never) to 6 (daily).

Psychosomatic symptoms. The General Health Questionnaire-12 (GHQ-12, Goldberg \& Williams, 1988) was used to investigate psychosomatic symptoms: social dysfunction (6 items, e.g., "Have you recently felt you couldn't overcome your difficulties?", a=.81), general dysphoria (4 items, e.g. "Have you recently lost much sleep through worry?", a=.82) and loss of confidence (2 items, e.g. "Have you recently being losing confidence in yourself?", $\alpha=.81$ ). Responses are rated on a four-point Likert scale that assesses how much the individual's present mental state differs from his/her usual state. The scale is differently worded for positive (from $0=$ better than usual/more so than usual, to $3=$ much less than usual) and for negative items (from 0=not at all, to 3=much more than usual).

Work dissatisfaction. In order to assess job dissatisfaction, we used the item by Aiken and colleagues (2002) "How much are you satisfied with your job?", rated on a four-point Likert scale ranging from 1 (very dissatisfied) to 4 (very satisfied). In order to assess job dissatisfaction, the scores have been reversed.

Intent to quit. One item was used to measure respondents' desire to leave their current job (Vahey Aiken, Sloane, Clarke, \& Vargas, 2004): COs were asked whether they had any plans to leave their present working position in the next 6 or 12 months. This item has been mainly used in previous research on healthcare personnel but, thanks to its generalizability, it may be used also for other types of occupational populations. The item is rated on a dichotomic response scale to contrast people who indicated they had plans to leave within the next year with those who did not. 


\section{Analysis Results}

The SPSS 19.0 software package for Windows was used to conduct all analyses. In order to verify the presence, and relative levels, of occupational stressors and well-being, descriptive statistics have been calculated. Then, Pearson's correlation analyses were conducted to examine bivariate correlations among stressors, measures of well-being, job dissatisfaction and intent to quit. Analysis of variance (ANOVA), allowed to investigate the presence of systematic differences in burnout dimensions among subjects of different age and work seniority. Finally, linear regression analyses were carried out to verify the influence exerted by stressors on well-being dimensions, and by burnout and dissatisfaction on intent to quit.

\subsection{Descriptive statistics and correlations}

Sources of stress. The most stressful factor was inconsiderate practices by management $(M=2.78, S D=1.06)$ whereas the less stressful factor was contact with inmates $(M=2.28, S D=0.79)$. Lack of relevant information $(M=3.01, S D=1.31)$ was found to be the most stress inducing among inconsiderate practice stressors, whereas fear of family members being hurt by an inmate $(M=1.69, S D=1.07)$ was found to be the less stress inducing among contact with inmates stressors.

Burnout level. The mean burnout level among COs was unexpectedly low, both in terms of exhaustion $(M=1.96$, $S D=1.52)$ and depersonalization $(M=1.71, S D=1.63)$. The item rated at the top of the exhaustion symptoms list was the feeling of being used up at the end of the workday $(M=2.49, S D=1.76)$, and the item rated at the top of the depersonalization symptoms list was the desire to do the job without being bothered $(M=2.19, S D=2.23)$.

Psychosomatic symptoms. An examination of participants' symptoms revealed that also general psychosomatic malaise level was low. In particular, the three most frequently reported symptoms among prison employees were: inability of concentration $(M=1.20, S D=0.65)$ among social dysfunction symptoms; feeling of being constantly under strain $(M=1.30, S D=0.97)$ among dysphoria symptoms; and loss of confidence in him/herself $(M=0.53, S D=0.80)$.

Job dissatisfaction. The level of job dissatisfaction was found to be relatively low $(M=2.36, S D=0.84)$, with $67.3 \%$ $(n=72)$ of respondents stating that they are quite or very satisfied with their job and only $13.1 \%(n=14)$ stating that they are not at all satisfied.

Intent to quit. A pattern of response similar to that found for job dissatisfaction was found for the intent to quit the job: only $10.2 \%$ ( $n=11)$ reported thinking to quit his/her job in the next $6 / 12$ months.

In order to verify the presence of significant relations among the considered variables, we have carried out bivariate correlations (see Table 1). Emotional exhaustion is especially related to stressful contact with inmates $(r=0.56$, $p<.01)$, and depersonalization to stressful contact with non-inmates $(r=0.57, p<.01)$; all the psychosomatic symptoms correlate with stressful contact with non-inmates: respectively, for general dysphoria $r=0.42(p<.01)$, for social dysfunction $r=0.34(p<.01)$, and for loss of confidence $r=0.36(p<.01)$. Finally, intent to quit is mainly related to emotional exhaustion $(r=0.35, p<.01)$.

Table 1. Means, Standard Deviations and Correlations of All Research Variables

\begin{tabular}{|c|c|c|c|c|c|c|c|c|c|c|c|}
\hline Variables & Mean $(S D)$ & 1 & 2 & 3 & 4 & 5 & 6 & 7 & 8 & 9 & 10 \\
\hline 1. Stressful Contact Non-Inmates & $2.48(0.75)$ & - & - & - & - & - & - & - & - & - & - \\
\hline 2. Stressful Contact with Inmates & $2.28(0.79)$ & $.508 * \star$ & - & - & - & - & - & - & - & - & - \\
\hline 3. Organizational Stressors & $3.53(0.95)$ & $.384^{\star \star}$ & $.452^{* *}$ & - & - & - & - & - & - & - & - \\
\hline $\begin{array}{l}\text { 4. Inconsiderate Practices by } \\
\text { Management }\end{array}$ & $2.76(1.09)$ & $.648^{\star \star}$ & $.360 * *$ & $.590 * *$ & - & & - & - & - & - & - \\
\hline 5. Emotional exhaustion & $1.96(1.52)$ & $.424^{\star \star}$ & $.561^{\star *}$ & $.380^{* *}$ & $.286^{\star *}$ & - & - & - & - & - & - \\
\hline 6. Depersonalization & $1.71(1.63)$ & $.572^{\star}$ & $.563^{\star *}$ & $.352^{\star *}$ & $.403^{\star *}$ & $.679 * *$ & - & - & - & - & - \\
\hline 7. General dysphoria & $1.00(0.73)$ & $.415^{\star}$ & $.348^{* *}$ & $.220^{*}$ & $.250 * \star$ & $.572^{\star \star}$ & $.565^{\star \star}$ & - & - & - & - \\
\hline 8. Social dysfunction & $1.03(0.46)$ & $.344^{\star *}$ & $.330 * \star$ & $.203^{*}$ & .161 & $.284^{\star \star}$ & $.336^{\star *}$ & $.569 * \star$ & - & - & - \\
\hline 9. Loss of confidence & $0.39(0.65)$ & $.355^{\star \star}$ & .123 & -.028 & $.194^{*}$ & $.229 *$ & $.405^{\star *}$ & $.524^{\star \star}$ & $.488^{*}$ & - & - \\
\hline 10. Job dissatisfaction & $2.64(0.84)$ & $.279 * *$ & $.258^{\star *}$ & .120 & .112 & $.458^{* *}$ & $.446^{\star *}$ & $.445^{\star \star}$ & $.276^{\star *}$ & $.216^{\star}$ & - \\
\hline 11. Intent to quit ${ }^{1}$ & $1.10(0.30)$ & .189 & $.342^{\star *}$ & .039 & .141 & $.345^{\star \star}$ & $.230^{*}$ & $.283^{* *}$ & .170 & $.222^{\star}$ & .188 \\
\hline
\end{tabular}

${ }^{1}$ Response scale: 1 (no) 2 (yes); * $p<.05 ;$ ** $p<.01$

\subsection{Differences among different groups}

Significant differences emerged from ANOVA analyses (carried out to verify the presence of differences in burnout dimensions for age and work seniority) were subjected to multiple comparisons using Bonferroni's highly significant 
difference to understand the nature of the differences. Demographic characteristics have been used as factors and the ANOVA indicated that participants of diverse age differed in exhaustion levels. More in detail, older COs (aged over 45) showed higher exhaustion mean score $(M=2.57, S D=1.83)$ if compared with younger ones, aged less than $33(M=1.52$, $S D=1.26)$, and this difference was statistically significant $(F=4.44, p<.05)$ (see Table 2). This is confirmed by the work seniority result: people employed as COs from more than 21 years showed higher exhaustion mean score $(M=2.24$, $S D=1.82)$ if compared with colleagues with a work seniority lesser than 10 years $(M=1.66, S D=1.32)$, even if this difference was not statistically significant $(F=1.36, p>.05)$.

Table 2. One-Way ANOVA: Differences in Burnout among Different Age Groups

\begin{tabular}{|c|c|c|c|c|c|}
\hline Burnout dimensions & Age & Mean (SD) & ANOVA F & d.f. & Bonferroni significance \\
\hline \multirow[t]{6}{*}{ Emotional exhaustion } & Up to 33 & $1.52(1.26)$ & 4.44 & 2 & $34-44$ \\
\hline & & & & & 45 and over* \\
\hline & $34-44$ & $1.85(1.30)$ & & & Up to 33 \\
\hline & & & & & 45 and over \\
\hline & 45 and over & $2.57(1.83)$ & & & Up to $33^{*}$ \\
\hline & & & & & $34-44$ \\
\hline \multirow[t]{6}{*}{ Depersonalization } & Up to 33 & $1.57(1.71)$ & 0.40 & 2 & $34-44$ \\
\hline & & & & & 45 and over \\
\hline & $34-44$ & $1.62(1.32)$ & & & Up to 33 \\
\hline & & & & & 45 and over \\
\hline & 45 and over & $1.90(1.83)$ & & & Up to 33 \\
\hline & & & & & $34-44$ \\
\hline
\end{tabular}

${ }^{*} p<.05$

\subsection{Predictors of burnout and psychosomatic symptoms}

Tables 3, 4 and 5 respectively show the results of the regression analysis (using the Enter method) for the objectives formulated on burnout, psychosomatic symptoms and intent to quit. For each single dependent variable, we have developed an independent regression model.

Table 3. Regression of Stressors on Burnout

\begin{tabular}{|c|c|c|c|c|}
\hline \multirow[t]{2}{*}{ Predictors } & \multicolumn{2}{|c|}{ Emotional Exhaustion } & \multicolumn{2}{|c|}{ Depersonalization } \\
\hline & $b(\mathrm{SE})$ & Beta & $b(\mathrm{SE})$ & Beta \\
\hline Stressful Contact with Non-Inmates & $\begin{array}{c}.434 \\
(.228)\end{array}$ & .216 & $\begin{array}{c}.800 \\
(.231)\end{array}$ & $.371^{\star *}$ \\
\hline Stressful Contact with Inmates & $\begin{array}{c}.789 \\
(.188)\end{array}$ & $.411^{\star \star}$ & $\begin{array}{c}.725 \\
(.190)\end{array}$ & $.351^{\star \star}$ \\
\hline Organizational Stressors & $\begin{array}{c}.274 \\
(.166)\end{array}$ & .172 & $\begin{array}{c}.079 \\
(.168)\end{array}$ & .046 \\
\hline Inconsiderate Practices by Management & $\begin{array}{l}-.144 \\
(.167)\end{array}$ & -.103 & $\begin{array}{c}.013 \\
(.069)\end{array}$ & .009 \\
\hline$R^{2}$ & \multicolumn{2}{|c|}{$.358 * \star$} & \multicolumn{2}{|c|}{$.430^{\star *}$} \\
\hline Adjusted $R^{2}$ & \multicolumn{2}{|c|}{.333} & \multicolumn{2}{|c|}{.408} \\
\hline
\end{tabular}

The first finding (see Table 3) is that stressful contact with inmates is the factor that has the most significant influence on burnout symptoms: emotional exhaustion (Beta $=.411, p<.01)$ and depersonalization (Beta $=.351, p<.01)$. 
Table 4. Regression of Stressors on Psychosomatic Symptoms

\begin{tabular}{|lcccccc|}
\hline Predictors & General dysphoria & \multicolumn{3}{c|}{ Social dysfunction } & \multicolumn{2}{c|}{ Loss of confidence } \\
\hline \multirow{2}{*}{ Stressful Contact with Non-Inmates } & $b(\mathrm{SE})$ & Beta & $b(\mathrm{SE})$ & Beta & $b(\mathrm{SE})$ & Beta \\
& .343 & $.354^{\star \star}$ & .199 & $.328^{\star}$ & .346 & $.400^{\star \star}$ \\
Stressful Contact with Inmates & $(.123)$ & & $(.079)$ & & $(.112)$ & \\
& .159 & .171 & .106 & .182 & -.005 & -.006 \\
Organizational Stressors & $(.101)$ & & $(.065)$ & & $(.093)$ & -.216 \\
& .036 & .047 & .047 & .098 & -.149 & \\
Inconsiderate Practices by Management & $(.089)$ & & $(.057)$ & & $(.082)$ & .064 \\
$R^{2}$ & -.046 & -.069 & -.074 & -.175 & .039 & $.082)$ \\
Adjusted $R^{2}$ & $(.090)$ & & $(.058)$ & & $(.082)$ \\
\end{tabular}

${ }^{\star} p<.05 ;{ }^{*} p<.01$

Instead of burnout, psychosomatich symptoms are mainly influenced by stressful contact with non-inmates, i.e. colleagues and superiors: general dysphoria (Beta $=.354, p<.01)$, loss of confidence (Beta $=.400, p<.01)$ and, to a lesser extent, social dysfunction (Beta $=.328, p<.05)$.

Table 5. Regression of Burnout and Job Dissatisfaction on Intent to Quit

\begin{tabular}{|c|c|c|}
\hline Predictors & \multicolumn{2}{|c|}{ Intent to Quit } \\
\hline & $b(\mathrm{SE})$ & Beta \\
\hline Emotional exhaustion & $\begin{array}{c}.068 \\
(.026)\end{array}$ & $.339 * \star$ \\
\hline Depersonalization & $\begin{array}{c}-.004 \\
(.024)\end{array}$ & -.021 \\
\hline Dissatisfaction & $\begin{array}{c}.015 \\
(.039)\end{array}$ & -.042 \\
\hline$R^{2}$ & & \\
\hline Adjusted $R^{2}$ & & \\
\hline
\end{tabular}

As regards the intent to quit, we have found a significant relation only with emotional exhaustion (Beta=.339, $p<.01)$, whereas no relations have been found with depersonalization nor with job dissatisfaction.

\section{Discussion}

The changing demographic features of the current workforce, for example the increased proportion of older people (Vaupel, 2010), press organizations in considering new employees' demands and needs. This should be done if organizations want to retain satisfied and committed workforce (Mohamed, Taylor \& Hassan, 2006).

The present study furthers our knowledge in different ways. With regard to the first aim - to verify the incidence of job stressors and the level of well-being among COs - unlike some previous studies (see for example Keinan \& MalachPines, 2007) participants of the present research don't seem to be exposed to substantial psychological stressors, neither show burnout nor psychosomatic complaints. This result is however in line with other previous studies on similar populations: for example, municipal police officers have shown relatively low burnout and psychosomatic manifestations (Setti \& Argentero, 2013). First, the awareness of doing a socially useful job and of giving a significant contribution to the community might protect these professionals from the risk of developing health troubles (Lavigne, Forest, \& CrevierBraud, 2012). Second, this result may mirror the specific-police culture, which is often used as a possible explanation of some negative aspects of this profession, such as the tendency to self-protection, secrecy and internal solidarity (Terpstra \& Schaap, 2013). This culture is also characterized by an old-fashioned machismo, in terms of a strong physical image that has to be externally shown (Crawley, 2004; Terpstra \& Schaap, 2013). Moreover, the work of COs could be considered an emotion work, as it requires to express specific (above all positive) emotions toward inmates (e.g., Zapf, 2002). The process by which positive emotions have to be displayed even though they are not in line with the truly felt 
ones (sometimes neutral or negative emotions), is defined emotional dissonance (Hochschild, 1983). Together considered, machismo culture and emotional dissonance may explain why participants of our study seem to have such a good health state: we suppose that their well-being could be, almost in part, ascribable to their need to show emotions different from the real ones. Regarding the type of stressors mainly reported by respondents, it is important to note that the factors inducing the highest levels of stress, such as lack of relevant information, are not directly related to working with prison inmates but could be found also in other work settings. This result suggests that stressors could be crosscultural, cross-occupational, and cross-organizational (see also Keinan \& Malach-Pines, 2007).

Our second aim was to verify if participants' age and work seniority are related to different levels of burnout, based on previous research which demonstrated a higher risk of developing burnout for COs with higher work seniority (Xanthakis, 2009). Our results partially confirm previous findings, as they show an increased level of burnout for older prison employees: the higher the age, the higher the level of exhaustion. But this is the only one significant finding: we have found statistically significant results neither for depersonalization, nor comparing participants by work seniority.

As regards the third aim of the present study, our findings suggest that the main predictor of burnout is stressful contact with inmates. This result is in line with Xanthakis (2009), who found that the quality of interactions with inmates is significantly associated with high levels of stress and burnout. Therefore, even if burnout is traditionally recognized as a syndrome mainly caused by chronic organizational features (Argentero \& Setti, 2008; Maslach, Schaufeli, \& Leiter, 2001), we may hypotesize that, for this particular population, stressful relations on the job, especially with inmates, may represent an important source of discomfort, that has to be considered besides organizational aspects. Furthermore, stressful relationships with colleagues and supervisors represent the only significant predictor of all the three psychosomatic symptoms. This result does not confirm previous research findings, which have shown that stress reactions are usually caused by organizational variables (see for example Giorgi \& Boldrini, 2011). But stressful contact with colleagues and supervisors refer to aspects such tensions caused by lack of privacy, work-family imbalance, ethnic tensions, which may be conceivably supposed to relate with psychosomatic troubles.

Concerning the fourth aim of the present research we start by saying that, as previosly found also by Keinan and Malach-Pines (2007), a substantial number of respondents appeared quite satisfied with their work and did not intend to leave it. More in detail, past research has demonstrated the influence of burnout and job dissatisfaction on the intent to quit among helping professions, such as nurses (Aiken et al., 2002; Lake, 1998). To the best of our knowledge, this is one of the first studies examining this specific relationship among prison employees, and our results are partially contrary to our expectations, as they did not show a significant interaction effect between dissatisfaction and intent to quit, whereas the only predictor that was found is emotional exhaustion.

These evidences have some practical implications that might be underscored. First, something should be said about possible interventions targeted at COs, both on an individual and on an organizational level (see Schaufeli \& Peeters, 2000). Effective strategies which may help individuals in coping with stressors are, for example, relaxation training, cognitive structuring, and stress inoculation (Stalgaitis, Meyers, \& Krisak, 1982). Organizational stretegies may consist, for example, in improving communication between supervisors and COs (Huckabee, 1992; Lindquist \& Whitehead, 1986), supporting COs who have experienced traumatic events (Finn, 1998), improving the selection processes (Dollard \& Winefield, 1994; Holgate \& Clegg, 1991), and mentoring new employees by senior ones (Klofas \& Toch, 1986). A further intervention may be counseling, already used in the prison service in order to reduce sickness absence caused by the contact with mental and behavioral disorders (Talbot-Landon, Palmer \& Flaxman, 2007). It could be useful in preventing emotional distress: in this view, counseling could be considered as a preventive measure, even if prison employees could be reluctant to use this type of service because of the fear of appearing weak, that is a typical aspect of their "macho" culture (Crawley, 2004; Liebling \& Maruna, 2005). But counseling could be really useful in supporting COs not only in reducing stress reactions, but also in accepting feelings of vulnerability.

This study naturally presents some limitations. First, a common problem is that our data are solely self-reported (Anderson, Coffey, \& Byerly, 2002). Moreover, the sample cannot be considered representative of the Italian context because of its small dimension and because data has been collected in an only one prison: this raises questions about the generalizability of our findings. Therefore, further investigations in other cities and in different geographic areas should be carried out to confirm our findings. Finally, not all the regression models explain a considerable portion of the variance: we can assume that other variables of interest have not been considered, for example emotional dissonance, which was found to be very important in accounting for psychological well-being of this population (Lewig \& Dollard, 2003). Therefore, it could be assessed in future studies, using specific instruments such as the Emotional Dissonance subscale of the Frankfurt Emotional Work Scale (FEWS; Zapf \& Holz, 2006).

Despite these difficulties, this study suggests that many of the relationships between stressors, burnout, psychosomatic symptoms, job dissatisfaction and intent to quit are quite robust. The future challenge could be not only to 
confirm their existence, but also to deepen the underlying dynamics.

\section{References}

Aiken, L. H., Clarke, S. P., Sloane D. M., Sochalski, J., \& Silber, J. H. (2002). Hospital nurse staffing and patient mortality, nurse burnout, and job dissatisfaction. JAMA, 288, 1987-1993.

Anderson, S. E., Coffey, B. S., \& Byerly, R. T. (2002). Formal Organizational Initiatives and Informal Workplace Practices: Links to WorkFamily Conflict and Job-Related Outcomes. Journal of Management, 28 (6), 787-810.

Argentero, P., \& Setti, I. (2008). Job perception, work conditions and burnout in emergency workers. Giornale Italiano di Medicina del Lavoro ed Ergonomia, Vol. 30, Suppl. A, Gennaio-Marzo 2008, A64.

Chapin, M., Brannen, S. J., Singer, M. I., \& Walker, M. (2008). Training police leadership to recognize and address operational stress. Police Quarterly, 11, 338-352.

Crawley, E. (2004). Doing prison work: The public and private lives of prison officers. Cullompton: Willan.

Dollard, M. F., \& Winefield, A. H. (1994). Organizational response to recommendations based on a study among correctional officers. International Journal of Stress Management, 1, 81-101.

Dowden, C., \& Tellier, C. (2004). Predicting workrelated stress in correctional officers: A metaanalysis. Journal of Criminal Justice, 32, $31-47$.

Dowler, K. (2005). Job satisfaction, burnout, and perception of unfair treatment: The relationship between race and police work. Police Quarterly, 8, 476-489.

Finn, P. (1998). Correctional officer stress: A cause for concern and additional help. Federal Probation, 62, 65-74.

Goldberg, D. P., \& Williams, P. (1988). A user's guide to the General Health Questionnaire. London: NFER-Nelson.

Health and Safety Executive (2006). Stress-related and psychological disorders. Retrieved from: www.hse.gov.uk/statistics/ causdis/stress.htm.

Hochschild, A. (1983). The managed heart: Commercialization of human feeling. Berkeley: University of California Press.

Holgate, A. M., \& Clegg, I. J. (1991). The path to probation officer burnout: New dogs, old tricks. Journal of Criminal Justice, 19, 325-337.

Huckabee, R. G. (1992). Stress in corrections: An overview of the issues. Journal of Criminal Justice, 20, 479-486.

Keinan, G., \& Malach-Pines, A. (2007). Stress and Burnout among Prison Personnel. Sources, Outcomes, and Intervention Strategies. Criminal Justice and Behavior, 34 (3), 380-398.

Klofas, J., \& Toch, H. (1986). The guard subculture myth. Journal of Research in Crime and Delinquency, 19, 238-254.

Kommer, M. M. (1990). Werken met mensen: Een onderzoek naar de werksituatie en functioneren van penitentiaire inrichtingswerkers [Working with people: A study on the working environment and the functioning of COs]. The Hague: Ministry of Justice.

Lake, E. T. (1998). Advances in understanding and predicting nurse turnover. Research in the sociology of health care, 15, 147-171.

Lambert, E., Edwards, C., Camp, C., \& Saylor, W. (2005). Here today, gone tomorrow, back again the next day: Antecedents of correctional absenteeism. Journal of Criminal Justice, 33, 165-175.

Lavigne, G. L, Forest, J., \& Crevier-Braud, L. (2012). Passion at work and burnout: A two-study test of the mediating role of flow experience. EJWOP, 21, 518-546.

Lewig, K. A., \& Dollard, M. F. (2003). Emotional dissonance, emotional exhaustion and job satisfaction in call centre workers. European Journal of Work and Organizational Psychology, 12 (4), 366-392.

Liebling, A., \& Maruna, S. (Eds.) (2005). The effects of imprisonment. Oregon: Willan Publishing.

Lindquist, C. A., \& Whitehead, J. T. (1986). Burnout, job stress and job satisfaction among southern correctional officers. Journal of Offender Counseling Services and Rehabilitation, 10, 5-26.

Maslach, C., Schaufeli, W. B., \& Leiter, M. P. (2001). Job burnout. Annual Review of Psychology, 52, 397-422.

Maslach, C., \& Jackson, S. E. (1986). Maslach Burnout Inventory: Second Edition. Palo Alto, CA: Consulting Psychologists Press.

Maslach, C., \& Leiter, M. P. (2008). Early Predictors of Job Burnout and Engagement. Journal of Applied Psychology, 93 (3), 498-512.

Meyer, J. P., Allen, N. J., \& Smith, C. A. (1993). Commitment to Organizations and Occupations: Extension and Test of a Threecomponent Conceptualization. Journal of Applied Psychology, 78, 538-551.

Mohamed, F., Taylor, G. S., \& Hassan, A. (2006). Affective Coinimtinent and Intent to Quit: The Impact of Work and Non-work Related Issues. Journal of Managerial Issues, XVIII (4), 512-529.

Prati, G., \& Boldrin, S. (2011). Fattori di stress e benessere organizzativo negli operatori di polizia penitenziaria. Giornale Italiano di Medicina del Lavoro ed Ergonomia (Supplemento B, Psicologia), 33 (3): B33-B39.

Schaufeli, W. B., Bakker, \& Van Rhenen, W. (2009). How changes in job demands and resources predict burnout, work engagement, and sickness absenteeism. Journal of Organizational Behavior, 30 (7), 893-917.

Schaufeli, W. B., \& Enzmann, D. (1998). The burnout companion to study and practice: A critical Analysis. London: Taylor \& Francis Ltd.

Schaufeli, W. B., \& Peeters, M. C. W. (2000). Job stress and burnout among correctional officers: a literature review. International Journal of Stress Management, 7, 19-48.

Schaufeli, W. B., Leiter, M. P., Maslach, C., \& Jackson, S. E. (1996). MBI-General Survey. Palo Alto (CA): Consulting Psychologists Press.

Sekaran, U. (1999). Understanding the dynamics of self concept of members in dual-career families. Human Relations 42, 97-116.

Senol-Durak, E., Durak, M., \& Gencoz, T. (2006). Development of work-stress scale for correctional officers. Journal of Occupational Rehabilitation, 16 (1), 157-168. 
Setti, I., \& Argentero, P. (2013). The influence of operational and organizational stressors on the well-being of municipal police officers. Medicina del Lavoro, 104 (5), 368-379.

Stalgaitis, S. J., Meyers, A. W., \& Krisak, J. (1982). A social learning theory model for reduction of correctional officers' stress. Federal Probation, 46, 33-41.

Talbot-Landon, S. D., Palmer, S., \& Flaxman, P. (2007). The development of an effective staff coaching programme for stress prevention and reduction in the Prison Service. The Coaching Psychologist, 3 (1), 24-27.

Temple, H., \& Gillespie, B. (2009). Taking charge of work and life. ABA Journal, 95(2), 31-32.

Terpstra, J., \& Schaap, D. (2013). Police culture, stress conditions and working styles. European Journal of Criminology 10 (1), $59-73$.

Toga, R., Binqela, T., \& Mjoli, T. Q. (2014). Job Satisfaction as a Moderator of the Relationship between Work-Family Conflict and Stress among Female Civil Service Managers. Mediterranean Journal of Social Sciences, 5 (2), 579-586.

Towl, G. J. (2005). National Offender Management Services: Implications for applied psychologists in probation and prison. Forensic Update, 81, April.

Vahey, D. C., Aiken, L. H., Sloane, D. M., Clarke, S. P., \& Vargas, D. (2004). Nurse Burnout and Patient Satisfaction. Medical Care, 42 (2), $1157-1166$.

Vaupel, J.W. (2010). Biodemography of human ageing. Nature, 464, 7288, 536-542.

Xanthakis, A. (2009). Levels of work-stress and burnout among prison officers. An examination of the need for a staff counselling service in a forensic setting. Counselling Psychology Review, 24 (3 \& 4), 100-118.

Zapf, D. (2002). Emotion work and psychological strain. A review of the literature and some conceptual considerations. Human Resource Management Review, 12, 237-268.

Zapf, D., \& Holz, M. (2006). On the positive and negative effects of emotion work in organisations. European Journal of Work and Organizational Psychology, 15, 1-28. 